\title{
A study of clinical spectrum of pseudo exfoliation syndrome
}

\author{
Triveni C. ${ }^{1}$, Divya $^{2}$, N. Lakshmi ${ }^{3}$, G. Sirisha ${ }^{4}$ \\ ${ }^{1}$ Dr. Chimata Triveni, Associate Professor, ${ }^{2}$ D. Divya, Senior Resident, ${ }^{3}$ Dr. N. Lakshmi, Professor \& HOD, \\ ${ }^{4}$ Dr. G. Sirisha, Professor, all authors are affiliated with Department of Ophthalmology, NRI Medical College, Guntur, \\ Andhra Pradesh, India.
}

Corresponding Author: Dr. Chimata Triveni, Department of Ophthalmology, NRI Medical College, Guntur, Andhra Pradesh, India. E-mail: trivenikrishna@gmail.com

\begin{abstract}
Background: Pseudoexfoliation syndrome (PXS) is the most common identifiable cause of secondary glaucoma, the prevalence of which varies considerably among different (PXF) ethnicities. Pseudoexfoliation is a genetically inherited condition. The prevalence of pseudoexfoliation increases with age. It is a common condition in the elderly population. This study aimed to assess the prevalence of and complications in patients with pseudo-exfoliation. Methods: This is an observational study performed in a sample of 103 patients (112 eyes) with pseudo-exfoliation for one year from October 2017-September-2018. Patients visiting the Ophthalmology department, NRI General Hospital, Chinakakani were enrolled in this study. Detailed evaluation including ophthalmic and general history, slit lamp biomicroscope, intraocular pressure measurement, gonioscopy and detailed eye examination was performed in all patients. Results: A total of 103 patients were analyzed; the major age group was 71-80 $(40.78 \%)$. Among the Male patients were found to be more $(66.02 \%)$. Majority of the patients were affected unilaterally $(91.26 \%)$ and remaining bilaterally $(8.24 \%)$. On slit-lamp examination degranulation of pupillary ruff and pseudoexfoliation material on the anterior capsule of the lens were present in $59.82 \%$ and $52.70 \%$ whereas corneal endothelium pigments, iris transillumination defects and pigments on the anterior lens capsule were absent in $82.1 \%, 91.1 \%$ and $68.80 \%$ respectively. All the cases were identified with PXF material on pupillary margin of the iris. Majority of the patients $(72.32 \%)$ had normal intraocular pressure. Glaucoma and ocular hypertension were seen in $20.53 \%$ and $7.14 \%$ of eyes. On gonioscopy, pseudoexfoliation material in the angle, pigments and sampaolesi's line were identified in $27.7 \%, 63.4 \%$ and $43.80 \%$ respectively. Only $8.69 \%$ of eyes had $6 / 24$ or better vision, while $8.69 \%$ had perception of light (PL) to No perception of light in PXF Glaucoma patients. Conclusion: The study concluded the need for early diagnosis and various complications involved in pseudoexfoliation.
\end{abstract}

Keywords: Pseudoexfoliation syndrome, Complications, Glaucoma, Iris pigmentation, Pupil, Trebeculary meshwork.

\section{Introduction}

Pseudoexfoliation syndrome (PXS) characterized by the deposition of distinctive fibrillar extracellular material in the anterior segment of the eye and was first described in 1917 by Lindberg [1]. It is frequently associated with a pen angle glaucoma known as pseudoexfoliation glaucoma. Elevated intraocular pressure, glaucoma, poor mydriasis, zonular weakness, corneal epitheliopathy and high rate of vitreous loss during cataract surgery are the complications in pseudoexfoliation syndrome. Glaucoma is the most severe co-morbidity associated with pseudoexfoliation syndrome. Deposition of pseudoexfoliation material, endothelial pigmentation, loss of pupillary ruff, iris

Manuscript received: $20^{\text {th }}$ August 2019

Reviewed: $30^{\text {th }}$ August 2019

Author Corrected: $8^{\mathrm{h}}$ September 2019

Accepted for Publication: $13^{\text {th }}$ September 2019 sphincter transillumination defects, sampaolesis line and pigment deposition in the trabecular meshwork are the clinical presentation of pseudoexfoliation syndrome [2]. Failure to dilate the pupil or to examine the lens with the slit lamp after dilation and low index of suspicion on the part of examiner are reasons for the misdiagnosis of pseudoexfoliation syndrome [2].

Pseudoexfoliation syndrome is mostly asymptomatic, and usually the increase in the intraocular pressure is painless. It leads to a delay in the identification of pseudoexfoliation syndrome in most of the patients.Late diagnosis can increase the risk of pseudoexfoliation syndrome. In the population, over the age of 60 years, the prevalence of pseudoexfoliation syndrome varies between 10 to $20 \%$ worldwide [3]. In India, it ranges 


\section{Original Research Article}

from $1.8 \%$ to $7.4 \%$ over the age of 45 years [4]. The prevalence of pseudoexfoliation syndrome is more in females [5]. Approximately around $25 \%$ of open-angle glaucoma is caused due to pseudoexfoliation syndrome [4]. The prevalence of pseudoexfoliation syndrome varies between age, gender, race, ethnicity and population. The incidence of pseudoexfoliation syndrome increases with age. Hence it is common in older people. The present study is conducted to determine the clinical profiles and various complications associated with pseudoexfoliation syndrome. To document the prevalence of ocular clinical profile of pattern and complications in patients with pseudo-exfoliative material attending general ophthalmology outpatient department of a tertiary care hospital.

\section{Materials and Methods}

The current study is an observational study conducted over a period of 1year, October 2017 to September 2018 in a sample of 112 eyes (103 subjects) of pseudo-exfoliation who met the below criteria were included.

Sampling methods: Convenience sampling

Sample size calculation: Complete enumeration

Source of data: Patients visiting in Department of Ophthalmology, NRI General Hospital, Chinakakani.

\section{Inclusion Criteria}

1. Age more than $45 y$ ears

2. All eyes with pseudoexfoliative material were included

\section{Exclusion Criteria}

1. Previous intraocular surgery.

2. History of trauma, uveitis.

3. Significant corneal opacities obscuring the anterior segment structures.

4. Any ocular pathology that could have led to secondary glaucoma.

5. Those patients who refuse to give consent.

Ethical considerations- After receiving the approval of the Institutional Ethics Committee, a written and informed consent was obtained from patients in his / her vernacular language.

Examination and investigations: A thorough clinical history was taken regarding the chief complaint, duration of disease and any other relevant history. A thorough clinical examination comprises of general and local examination.

Which includes: General examination, Vital data, anemia, icterus, cyanosis, clubbing, pedal edema, lymphadenopathy, Cardiovascular and respiratory system examination.

Ocular examination: Visual acuity of both eyes was recorded unaided and with pinhole. All patients were examined with a slit lamp after mydriasis with phenylephrine. The diagnosis of exfoliation of syndrome was made on the basis of presence of Greyish white dandruff-like flaky deposits on Pupillary margin of iris, Anterior capsule of lens - in papillary, retro-iridal portion, Zonule (wherever visible), Anterior face of vitreous., Pigment dispersion from iris especially the atrophic patches, seen as transillumination defects. Pigment deposits over, Posterior surface of cornea, the anterior capsule of the lens.

Then gonioscopy examination was done with the help of Goldman four mirror gonioscope, in a dark room and with use of short, narrow slit-beam to avoid constricting of pupil and artificially opening the angle. For this cornea was anaesthetized by instilling $0.5 \%$ proparacaine eye drops in conjunctival sac. The angle of anterior chamber was examined. The following findings were looked for Pseudo-exfoliation material deposits over different structures in angle, Pigments over trabecular meshwork, Sampaolesi's line, Width of the angle of anterior chamber as per Shaffer grading system is given below (Table 1) 
Table-1: Shaffer grading system.

\begin{tabular}{|c|c|c|c|}
\hline Grade 0 & $0^{0}$ & Irido-corneal contact & Closed-angle \\
\hline Grade 1 & $10^{0}$ & SL and part of TM visible & Very narrow-angle \\
\hline Grade 2 & $10^{0}-20^{0}$ & TM visible & Moderately narrow \\
\hline Grade 3 & $20^{0}-35^{0}$ & SS visible & Moderately wide angle \\
\hline Grade 4 & $35^{0}-45^{0}$ & CBB visible & Wide angle \\
\hline
\end{tabular}

Intraocular pressure estimation with Goldman applanation tonometer was done in all patients after anaesthetizing cornea with $0.5 \%$ Proparacaine eye drops in the conjunctival sac. The ophthalmoscopic examination was done whenever possible.

Eyes with intraocular pressure greater than $21 \mathrm{mmHg}$, with glaucomatous cupping and visual field loss, were categorized as glaucoma while those with intraocular pressure greater than $21 \mathrm{~mm} \mathrm{H}$ but with normal visual fields and optic disces were labelled as ocular hypertension.

Data analysis: Descriptive analysis was carried out by mean and standard deviation for quantitative variables, frequency and proportion for categorical variables. The association between explanatory variables and categorical outcomes was assessed by cross tabulation and comparison of percentages. IBM SPSS version 22 was used for statistical analysis [6].

\section{Result}

A total of 103 (112 eyes) subjects were included in the final analysis.

The mean age was $68.47 \pm 9.37$ years. Among the study population $4(3.88 \%)$ were aged up to 50 years, $17(16.50 \%)$ were aged between 51 to 60 years, $34(33.01 \%)$ were aged between 61 to 70 years, $42(40.78 \%)$ were aged between 71 to 80 years and remaining $6(5.83 \%)$ were aged 81 years and above. Among the study population, 68(66.02\%) participants were male and remaining $35(33.98 \%)$ were female. (Table 2)

Table-2: Descriptive analysis of age, gender in study population $(\mathrm{N}=103)$.

\begin{tabular}{|l|c|}
\hline Parameter & Summary \\
\hline Age Mean \pm SD & $68.47 \pm 9.37$ \\
\hline Age group & \multicolumn{2}{|c|}{} \\
\hline Up to 50 years & $17(16.50 \%)$ \\
\hline 51 to 60 & $34(33.01 \%)$ \\
\hline 61 to 70 & $42(40.78 \%)$ \\
\hline 71 to 80 & $6(5.83 \%)$ \\
\hline 81 years and above & \multicolumn{2}{|c|}{} \\
\hline Gender & $68(66.02 \%)$ \\
\hline Male & $35(33.98 \%)$ \\
\hline Female & \multicolumn{2}{|c|}{} \\
\hline
\end{tabular}

Among the study population, 94 (91.26\%) patients had unilateral pseudo explosion while the rest had bilateral 9 (8.24\%). On slit-lamp examination, $20(17.90 \%)$ eyes had corneal endothelium pigments. Among the study population all 112 (100\%) had PXF material on pupillary margin of the iris, $67(59.82 \%)$ eyes had degranulation of pupillary ruff. 10 (8.90\%) eyes had Iris Transillumination defects, 73 (65.13\%) eyes had anterior lens capsule PXF in pupil, 59 (52.70\%) eyes had anterior lens capsule Retro-iris PXF, 35 (31.30\%) had anterior lens capsule pigments., 25 (22.32\%) had IMSC lens changes, 5(4.46\%) had MC, 55 (49.11\%) had NS, 5 (4.46\%) had Phacodonesis and 4 (3.57\%) had PSCC (Table 3). 
Table-3: Descriptive analysis of study population $(\mathrm{N}=112)$ eyes.

\begin{tabular}{|c|c|}
\hline Parameter & Summary \\
\hline \multicolumn{2}{|l|}{ Laterality } \\
\hline Unilateral & $94(91.26 \%)$ \\
\hline Bilateral & $9(8.24 \%)$ \\
\hline \multicolumn{2}{|c|}{ Slit-lamp examination } \\
\hline \multicolumn{2}{|c|}{ Corneal Endothelium Pigments } \\
\hline Present & $20(17.90 \%)$ \\
\hline Absent & $92(82.1 \%)$ \\
\hline \multicolumn{2}{|c|}{ PXF material on the pupillary margin of IRIS } \\
\hline Present & $112(100 \%)$ \\
\hline Absent & $0(0 \%)$ \\
\hline \multicolumn{2}{|c|}{ Degranulation of pupillary RUFF } \\
\hline Present & $67(59.82 \%)$ \\
\hline Absent & $45(40.18 \%)$ \\
\hline \multicolumn{2}{|c|}{ Iris Transillumination defects } \\
\hline Present & $10(8.90 \%)$ \\
\hline Absent & $102(91.1 \%)$ \\
\hline \multicolumn{2}{|c|}{ Anterior lens capsule PXF In Pupil } \\
\hline Present & $73(65.13 \%)$ \\
\hline Absent & $39(34.82 \%)$ \\
\hline \multicolumn{2}{|c|}{ Anterior lens capsule Retro-iris PXF } \\
\hline Present & $59(52.70 \%)$ \\
\hline Absent & $53(47.30 \%)$ \\
\hline \multicolumn{2}{|c|}{ Anterior lens capsule Pigments } \\
\hline Present & $35(31.30 \%)$ \\
\hline Absent & $77(68.80 \%)$ \\
\hline \multicolumn{2}{|l|}{ Lens Changes } \\
\hline IMSC & $25(22.32 \%)$ \\
\hline $\mathrm{MC}$ & $5(4.46 \%)$ \\
\hline NS & $55(49.11 \%)$ \\
\hline Phacodonesis & $5(4.46 \%)$ \\
\hline PSCC & $4(3.57 \%)$ \\
\hline Absent & $18(16.07 \%)$ \\
\hline
\end{tabular}

The mean IOP was $21.98 \pm 12 \mathrm{~mm}$ Of Hg. Among the study population,81 (72.32\%) had normal IOP, 8 (7.14\%) had Ocular hypertension, and $23(20.53 \%)$ had glaucoma. Among the study population,13(11.80\%) had Fundus Details hazy,18 (16.10\%) had FUNDUS changes. (Table 4)

Table-4: Summary of IOP and fundus changes $(\mathrm{N}=112)$.

\begin{tabular}{|l|c|}
\hline Parameter & Summary \\
\hline IOP In mm Of Hg (Mean \pm SD) & $21.98 \pm 12$ \\
\hline$*$ Normal & $81(72.32 \%)$ \\
\hline$* *$ Ocular hypertension & $8(7.14 \%)$ \\
\hline$* * *$ Glaucoma & $23(20.53 \%)$ \\
\hline Fundus Changes & $13(11.80 \%)$ \\
\hline Details hazy & $18(16.10 \%)$ \\
\hline Present & $81(72.30 \%)$ \\
\hline Absent & \\
\hline
\end{tabular}


*IOP $<22 \mathrm{~mm}$ of $\mathrm{Hg}$ with no fundus and Visual field changes

$* *$ IOP $>22 \mathrm{~mm}$ of $\mathrm{Hg}$ with no fundus and Visual field changes

$* * *$ IOP $>22 \mathrm{~mm}$ of $\mathrm{Hg}$ with fundus and Visual field changes

Among the study, population31(27.7\%) eyes had a gonioscopy PXF angle. Among the study population 71 (63.4\%) eyes had gonioscopy pigments. Among the study population 49 (43.80\%) eyes had gonioscopy sampaolesi's line. Among the study population, 67 (59.82\%) eyes had GONIOSCOPY Shaffer's Grade IV, 31 (27.68\%) eyes had grade III, 9 (8.04\%) had grade II and remaining 5 (4.46\%) eyes had GONIOSCOPY Shaffer's grade I (Table 5).

Among the study population 2 (8.69\%) had no PL, 14 (60.87\%) had PL - 3/60, 5 (21.74\%) had visual activity 4/ 60-6/36, $5(21.74 \%)$ had visual activity 6/24-6/6 (Table 6).

Table-5: Summary of Gonioscope findings

\begin{tabular}{|l|c|}
\hline Gonioscopy PXF in angle & $31(27.7 \%)$ \\
\hline Present & $81(72.30 \%)$ \\
\hline Absent & $71(63.4 \%)$ \\
\hline Gonioscopy Pigments & $41(36.60 \%)$ \\
\hline Present & \\
\hline Absent & $49(43.80 \%)$ \\
\hline Gonioscopy Sampaolesi's line & $63(56.3 \%)$ \\
\hline Present & \\
\hline Absent & $67(59.82 \%)$ \\
\hline Gonioscopy Shaffer's Grade & $31(27.68 \%)$ \\
\hline GradeIV & $9(8.04 \%)$ \\
\hline GradeIII & $5(4.46 \%)$ \\
\hline GradeII & \\
\hline GradeI & \\
\hline
\end{tabular}

Table-6: Visual status in pseudo-exfoliative glaucoma subjects

\begin{tabular}{|c|c|c|}
\hline Visual Acuity & No. of Eyes & Percentage \\
\hline No PL & 2 & $8.69 \%$ \\
\hline PL-3/60 & 14 & $60.87 \%$ \\
\hline $4 / 60-6 / 36$ & 5 & $21.74 \%$ \\
\hline $6 / 24-6 / 6$ & 2 & $8.69 \%$ \\
\hline Total & $\mathbf{2 3}$ & $\mathbf{2 0 . 5 3 \%}$ \\
\hline
\end{tabular}

Table-7: Prevalence of angle status in glaucomatous, ocular hypertension and normal XFS eyes $(\mathrm{N}=112)$

\begin{tabular}{|c|c|c|c|c|}
\hline Angle Status & Glaucomatous Eyes & Ocular Hypertension Eyes & Normal XFS Eyes & Total Eyes \\
\hline Grade IV & $14(60.87 \%)$ & $3(37.5 \%)$ & $50(61.73 \%)$ & 67 \\
\hline Grade III & $5(21.74 \%)$ & $2(25.0 \%)$ & $24(29.63 \%)$ & 31 \\
\hline Grade II & $3(13.04 \%)$ & $2(25.0 \%)$ & $4(4.94 \%)$ & 9 \\
\hline Grade I & $1(4.35 \%)$ & $1(12.5 \%)$ & $3(3.70 \%)$ & 5 \\
\hline Total eyes & $23(100 \%)$ & $8(100 \%)$ & $81(100 \%)$ & 112 \\
\hline
\end{tabular}

Among the glaucomatous eyes, 14 (60.87\%) had Grade IV angle status, 5 (21.74\%) had grade III, 3 (13.04\%) had grade II, $1(4.35 \%)$ had grade I angle status. Among the ocular hypertension eyes $3(37.5 \%)$ had Grade IV angle status,2 (25.0\%) had grade III, 2 (25.0\%) had grade II, 1 (12.5\%) had grade I angle status. Among the normal XFS eyes 50 $(61.73 \%)$ had Grade IV angle status, 24 (29.63\%) had grade III, 4 (4.94\%) had grade II, 13 (3.70\%) had to grade I angle status (Table 7). 


\section{Discussion}

Worldwide, pseudoexfoliation is the most common cause of open and closed-angle glaucoma. It is associated with zonular weakness, delayed dislocation of the crystalline and intraocular lens. The prevalence of pseudoex foliation may vary based on the region and the study design. In most of the studies, the prevalence ranges between $0.69-23 \%$. In Indian population it was about $0.69-3.8 \%$ [7]. The presence of pseudoex foliation can increase the complications involved in cataract surgery. In this present study, the prevalence and complication in pseudo exfoliation were determined.

A total of 103 pseudoexfoliation patients were identified during the study period. The Mean \pm SD in the study population was $68.47 \pm 9.37$. Philip, S.S. et al [4], performed a study in 529 participants in which the Mean \pm SD was $65.1 \pm 8.0$. In a study conducted by Arvind, H. et al [8], in a population of 108 subjects in South India the Mean \pm SD was 64.7 \pm 9.63 . The results of the present resembles with Shazly, T.A. et al [9], performed in 320 subjects in which the Mean \pm SD was $68.15 \pm 8.16$ years. Pseudoex foliation is an age-related syndrome, so the incidence of pseudoex foliation increases with age.

Among 103 pseudoexfoliation patients, majority of the then were between the age group of 71-80 years of age with $40.78 \%$ followed by $61-70$ years of age with $33.01 \%$.Itresembles the Sathish, G. et al [10], study conducted in a population of 22 pseudoexfoliation patients in which 53\%was belonged to the age group of $71-80$ years with $53 \%$ followed by the age group of 61 70 years with $27 \%$. The prevalence and mean age of pseudoexfoliation may vary based on age, race and geographic locations.

In the present study, the majority of the patients were males, with $66.02 \%$ followed by females with $33.98 \%$.Joshi, R., et al [7], conducted a study in which out of 226 pseudoexfoliation cases, 119 patients were males $(52.7 \%)$ and 107 were females $(47.3 \%)$. In most of the studies, the predominance of males was more as compared to females. In a study performed by Hemalatha, B.C. et al [11], out of 50 cases, 32 were male patients, and 18 were female patients. High ultraviolet exposure may be one of the reasons for male predominance in the Indian population. Among 103 cases, majority of the patients was affected with a unilateral pseudoexfoliation with $91.26 \%$ and $8.24 \%$ with bilateral pseudoexfoliation. Herry, J.C. et al [12], conducted a retrospective study on 347 participants in which 225 cases were identified unilateral whereas 122 with bilateral pseudoexfoliation. The current study result was similar to the Philip, S.S. et al [4], performed in a population of 529 patients in which majority of the patients was identified with the unilateral pseudoexfoliation with $57.8 \%$ followed by bilateral with $42 \%$. In some studies, the bilateral cases predominate unilateral cases because patient with unilateral pseudoexfoliation can be progressed to bilateral with the age and duration of the condition. The prevalence can vary based on the clinical profile and optical coherence tomography characteristics.

In the present study on slit-lamp examination, $17.90 \%$ of eyes had pigments on the corneal endothelium, and $4.46 \%$ had phacodonesis. Sharma, P. et al [13], conducted a study in a population of 93pseudo exfoliation patients in which $49.4 \%$ showed pigments on the corneal endothelium and $8.23 \%$ have phacodonesis. Presence of the corneal endothelium pigments and phacodonesis helps to identify patients with pseudoexfoliation.

Among 103 cases, 59.82\% of patients were presented with degranulation of pupillary ruff. In a retrospective observational study performed by Rao, AD. et al [14], out of 346 patients with pseudoexfoliation, the pupillary ruff atrophy was common in all forms of deposition. Rao, A et al [15], conducted a study in which slit-lamp examination identified 16 patients with pupillary ruff atrophy in 32 unilateral pseudoexfoliation cases and 38 of 59 bilateral cases. The degranulation of pupillary ruff showed by $74.7 \%$ of eyes in the study conducted by Sharma, P. et al [13].

In the current study, the pseudoexfoliation material on the pupillary margin was present in all the patients who are similar to the results of Sharma, P. et al [13], study in which $84.7 \%$ of patients were identified with the pseudoexfoliation material on the pupillary margin. Among the study population, $65.13 \%$ of eyes had anterior lens capsule PXF in pupil. In Sharma, P. et al [13], study performed in a population of 93 patients $91.7 \%$ showed pseudoexfoliation material on the anterior capsule of the lens.

The mean intraocular pressure $(\mathrm{mmHg})$ in the present study population was $21.98 \pm 12$. In a cross-sectional study conducted in a population of 91 subjects by Rao, A. et al [15] in which $18 \pm 3.4$ was the mean IOP in patients with unilateral pseudoexfoliation while $20 \pm 1.2$ in the bilateral pseudo exfoliation cases. Thomson, R. et al [16], performed a cross-sectional study in the 


\section{Original Research Article}

southern population of India in which the mean $\pm \mathrm{SD}$ of intraocular pressure was $24.14 \pm 1.4 \mathrm{mmHg}$. The presence of pseudoexfoliation is associated with increased intraocular pressure in the eyes.

The intraocular pressure was normal in $72.32 \%$ of eyes in the study population, $7.14 \%$ showed the presence of ocular hypertension and $20.53 \%$ were identified with glaucoma. In Sharma, P. et al [13], study intraocular pressure was normal in $79.4 \%$ of pseudoex foliation patients. Ocular hypertension and glaucoma were identified in $1.8 \%$ and $18.8 \%$ of participants respectively. The prevalence of ocular hypertension is more as compared to glaucoma patients. The delay in the diagnosis of pseudo exfoliation can converts ocular hypertension patients to glaucoma.

In the current study, gonioscopy showed pseudo exfoliation angle in $27.7 \%$ eyes. Al- Saleh, S.A., et al [2], study the pseudoexfoliation material in the angle showed by $23.9 \%$ right eye of the patients and $14.9 \%$ of left eye.

In the present study pseudo exfoliation pigmentation was observed in $63.4 \%$ of patients which is similar to the Al- Saleh, S.A., et al [2], study conducted in a population of 69 patients in the pseudoexfoliation pigmentation was seen in the right eye of the $58.7 \%$ patients whereas $53.3 \%$ identified in the left eye.

Among the study population, $43.80 \%$ of eyes had gonioscopy sampaolesi's line which resembles the study result of Sharma, P. et al [13], in which $47.5 \%$ showed gonioscopy sampaolesi's line.

In the present study $8.69 \%$ of pseudoexfoliation eyes had perception of light to Noperception of light, $60.87 \%$ had had the perception of light to $3 / 60$, and also only $8.69 \%$ of eyes had $6 / 24$ or better vision. In a study conducted by Sharma, P. et al [13], in the Indian population $65.6 \%$ had the perception of light to nil vision while $6.3 \%$ had $6 / 24$ or better vision.

The prevalence of pseudoexfoliation increases with a decrease in visual activity. Increased intraocular pressure and poor response of the patients to medication can lead to optic nerve and visual fields damage. It can eventually cause poor vision.

\section{Limitations of the study}

1. The sample size included in the study was not sufficient

2. Present study results cannot be generalised.

\section{Conclusion}

Pseudoexfoliation is a common age-related condition. The prevalence of pseudoexfoliation can vary and is mostly seen in the elderly population. It increases the complications involved in cataract surgery. In the present study population majority of the patients were males with $68.47 \pm 9.37$ mean $\pm \mathrm{SD}$. Most of the cases were identified as unilateral pseudoexfoliation. On slitlamp examination degranulation of pupillary ruff and pseudoexfoliation material on the anterior capsule of the lens were identified with $59.82 \%$ and $52.70 \%$ respectively. The corneal endothelium pigments, iris transillumination defects and pigments on the anterior lens capsule were absent in $82.1 \%, 91.1 \%$ and $68.80 \%$ cases respectively. All the cases were identified with PXF material on pupillary margin of the iris. Majority of the patients in the present study had normal intraocular pressure. Glaucoma and ocular hypertension were seen in $20.53 \%$ and $7.14 \%$ of eyes. On gonioscopy examination pseudoexfoliation in the angle, pigments and sampaolesis line were identified in $27.7 \%, 63.4 \%$ and $43.80 \%$ of patients. Among the study population $8.69 \%$ had no PL, $60.87 \%$ had PL - 3 / 60, 21.74\% had visual activity 4 / $60-6$ / 36, 21.74\% had visual activity $6 / 24-6 / 6$.

\section{What the study adds to the existing knowledge?}

The present study helps to determine the prevalence and complications involved in pseudoexfoliation. The prevalence and complications of pseudoexfoliation are increasing in the population. It is common in older people hence the need for awareness of pseudoexfoliation is more. Delay in seeking medical attention leads to various comorbidities. The early detection and effective management can reduce the morbidities associated with pseudoexfoliation.

\section{Author's contribution}

Dr. Chimata Triveni: Conceptualized the study and played primary role in compiling, analysis and interpretation of the data. All the drafts were prepared, reviewed and final draft was approved.

Dr. Divya, N. Lakshmi and Dr. G. Sirisha: Fine tuning of the proposal, contributed in data collection and entry. Reviewed the results and contributed to preparation and review of drafts.

All the authors have read and approved final version of the manuscript. All the authors take complete responsibility for the content of the manuscript. 


\section{Original Research Article}

Acknowledgements: Authors would like to acknowledge the technical support in data entry, analysis and manuscript editing by "Evidencian Research Associates.”

\section{Declarations}

Funding: Nil, Conflict of interest: Nil

Permission from IRB: Yes

Ethical approval: not necessary

\section{References}

1.Naumann GO, Schlotzer-Schrehardt U, Kuchle M. Pseudoexfoliation syndrome for the comprehensive ophthalmologist. Intraocular and systemic manifestations. Ophthalmol. 1998;105(6):951-968. doi:10. 1016 / S0161-6420 (98)96020-1.

2.Al-Saleh SA, Al-Dabbagh NM, Al-Shamrani SM, Khan NM, Arfin M, Tariq M, et al. Prevalence of ocular pseudoexfoliation syndrome and associated complications in Riyadh, Saudi Arabia. Saudi Med J. 2015; 36(1): 108-112. doi:10.15537/smj.2015.1.9121.

3.Schlotzer-Schrehardt U, Naumann GO. Ocular and systemic pseudoexfoliationsyndrome.Am J Ophthalmol. 2006;141(5):921-937. doi:10.1016/j.ajo.2006.01. 047.

4.Philip SS, John SS, Simha AR, Jasper S, Braganza AD. Ocular clinical profile of patients with pseudoexfoliation syndrome in a tertiary eye care center in South India. Mid East Afr J Ophthalmol. 2012;19(2):231-236. doi:10.4103/0974-9233.95259.

5.Karger RA, Jeng SM, Johnson DH, Hodge DO, Good MS.Estimated incidence of pseudoexfoliation syndrome and pseudoexfoliation glaucoma in Olmsted County, Minnesota. J Glauc. 2003;12(3):193-197. doi: 10.1097/ 00061 198-200306000-00002.

6.IBM Corp. Released 2013. IBM SPSS Statistics for Windows, Version 22.0. Armonk, NY: IBM Corp.

7.Joshi RS, Singanwad SV. Frequency and surgical difficulties associated with pseudoexfoliation syndrome among Indian rural population scheduled for cataract surgery: Hospital-based data. Ind J Ophthal. 2019;67(2): 221-226. doi:10.4103/ijo.IJO_931_18.
8.Arvind H, Raju P, Paul PG, Baskaran M, Ramesh SV, George RJ, et al. Pseudoexfoliation in South India. British J Ophthalmol. 2003;87(11):1321-1323. doi:10. 1136/ bjo.87.11.1321.

9.Shazly TA, Farrag AN, Kamel A, Al-Hussaini AK. Prevalence of pseudoexfoliation syndrome and pseudoexfoliation glaucoma in Upper Egypt. BMC Ophthal. 2011;11(1):18. doi:10.1186/1471-2415-11-18.

10. Elias E, Sathish G. Patterns of pseudoexfoliation deposits and its relation to intraocular pressure and retinal nerve fiber layer defects. TNOA J Ophthal Sci Res.2018;56(3):146-149. doi:10.4103/tjosr.tjosr_67_18.

11. Hemalatha BC, Shetty SB. Analysis of Intraoperative and Postoperative Complications in Pseudoexfoliation Eyes Undergoing Cataract Surgery. J Clinic Diagnos Res: JCDR. 2016;10(4):NC05-NC08. doi:10.7860/JCDR/2016/17548. 7545.

12. Henry JC, Krupin T, Schmitt M, Lauffer J, Miller E, Ewing MQ, et al. Long-term follow-up of pseudoexfoliation and the development of elevated intraocular pressure. Ophthalmol.1987;94(5):545-552. doi:10.1016/ s0161-6420(87)33413-x.

13. Sharma PD, Kumar Y, Shasni RN. Pattern of pseudoexfoliation syndrome in lower to mid himalayan region of shimla hills in India. J Evol Med Dental Sci. 2013;2(52):10098-10106. doi: 10.14260/jemds/1742.

14. Rao A, Padhy D. Pattern of pseudoexfoliation deposits on the lens and their clinical correlation-clinical study and review of literature. PloS one. 2014;9 (12):e113329. doi:10.1371/journal.pone.0113329.

15. Rao A. Clinical and Optical Coherence Tomography Features in Unilateral versus Bilateral Pseudoexfoliation Syndrome. J Ophthal Vis Res. 2012;7(3):197202.

16. Thomas R, Nirmalan PK, Krishnaiah S. Pseudoexfoliation in southern India: the Andhra Pradesh Eye Disease Study. Invest Ophthalmol Vis Sci. 2005; 46 (4):1170-1176. doi:10.1167/iovs.04-1062.

\section{How to cite this article?}

Triveni C, Divya, N. Lakshmi, G. Sirisha. A study of clinical spectrum of pseudoexfoliation syndrome. Trop J Ophthalmol Otolaryngol.2019; 4(5):341-348. doi:10.17511/jooo.2019.i05.06 